\title{
A psicomotricidade como coadjuvante no tratamento fisioterapêutico
}

\author{
Hugo Alves de Souza ${ }^{l}$ \\ José Roberto Pimenta de Godoy ${ }^{2}$
}

RESUMO - A psicomotricidade visa facilitar a interação entre a motricidade, a afetividade e a mente, pois acredita que o desenvolvimento motor normal está diretamente relacionado com esses três fatores que devem ser observados durante a abordagem psicomotora. Os participantes de uma terapia psicomotora são estimulados a interferir em cada exercício proposto, pois o objetivo final da tarefa é proporcionar experiências significativas aos participantes. A interação entre a fisioterapia e a psicomotricidade pode tornar o tratamento fisioterapêutico mais eficaz e significativo tanto para o paciente como para o fisioterapeuta.

Palavras-chave: psicomotricidade, fisioterapia, interação entre as áreas.

\section{Psichomotricity and physiotherapy}

\begin{abstract}
The psichomotricity seeks to facilitate the interaction among the motricity, affectivity and the mind, because it believes that the normal motor development is directly related with those three factors that should be observed during the psichomotricity approach. The participants of the psichomotricity therapy are stimulated to infer in each proposed exercise, therefore the final purpose of the task is to provide significant experiences to the participants. The interaction between the physiotherapy and the psichomotricity can turn the physiotherapic treatment more effective and so much significant for the patient as for the physiotherapist.
\end{abstract}

Key words: psichomotricity, physiotherapy, interaction among the areas.

\footnotetext{
${ }^{1}$ Acadêmico do $9^{\circ}$ período do curso de Fisioterapia do Centro Universitário de Brasília-UniCEUB.

${ }^{2}$ Mestre em Ciências da Saúde pela UnB; doutorando em Ciências da Saúde pela UFRN, professor de Anatomiae Neuroanatomia do Centro Universitário de Brasília-UniCEUB.E-mail: jose62521@uniceub.br
}

Univ. Ci. Saúde, Brasília, v. 3, n. 2, p. 287-296, jul./dez. 2005 
A psicomotricidade pode ser definida como uma ciência que tem como objeto de estudo o homem por meio de sua relação com o mundo externo e interno. Está dividida em três campos distintos: reeducação psicomotora - que visa corrigir alterações no desenvolvimento psicomotor, tais como, equilíbrio, coordenação, dispraxia; terapia psicomotora - que se refere a todos os casos nos quais a dimensão afetiva ou relacional parece dominante na instalação inicial do transtorno; educação psicomotora - que visa desenvolver, na criança, a capacidade de criar, resolver e adaptar as tarefas realizadas, sem usar a imposição como método de educação1.

Coffito (1987) considera a Fisioterapia:

"como uma ciência aplicada, cujo objetivo de estudo é o movimento humano em todas as suas formas de expressão e potencialidades, quer nas suas alterações patológicas, quer nas suas repercussões psíquicas e orgânicas, com objetivos de preservar, manter, desenvolver ou restaurar a integridade de um órgão ou sistema".

Para esse propósito, lança mão de recursos e conhecimentos próprios fundamentados nas produções científicas atuais. Como a Fisioterapia pertence às Ciências Médicas, exige-se que busque aperfeiçoar seus processos terapêuticos para o benefício da população².

A interação entre diferentes áreas de conhecimento é cada vez mais comum, já que os resultados alcançados nas experiências multidisciplinares têm demonstrado sucesso. Portanto, a associação das técnicas fisioterápicas aos conceitos das técnicas psicomotoras vem somar-se ao tratamento fisioterapêutico trazendo o lúdico à terapia física e a importância de considerar o indivíduo como um todo evitando dissociar o corpo da mente 3 . Logo, o objetivo do presente trabalho é verificar, na literatura atual, artigos que associem técnicas psicomotoras ao tratamento fisioterapêutico.

\section{A psicomotricidade}

A psicomotricidade é uma ciência relativamente nova. Seu surgimento ocorreu no início do século XX, na França, durante a epidemia de encefalite ${ }^{4}$.

Visa facilitar a interação entre a motricidade, a afetividade e a mente, pois acredita que o desenvolvimento motor normal das pessoas está relacionado com esses três fatores. Com isso, desconsidera a divisão do indivíduo em partes motora,

\footnotetext{
${ }^{1}$ BOATO, 1996.

${ }^{2}$ NICIDA, 2004.

${ }^{3}$ BOATO, 1996.

${ }^{4}$ AUCOUTURIER et al., 1986. 
afetiva e intelectual, no momento do atendimento clínico. Assim, faz a abordagem clínica voltada à globalidade do indivíduo, uma vez que, na sua concepção, a dinâmica aplicada será capaz de desenvolver o aspecto motor no momento da execução da atividade, o aspecto intelectual ao procurar resolver o desafio proposto e o aspecto afetivo, já que, no decorrer da atividade, o participante experimentará sentimentos diversos ${ }^{5}$.

Como justificativa para esta forma de proceder, a psicomotricidade fundamenta-se no funcionamento do sistema nervoso em que uma parte não pode operar de modo independente dos outros constituintes, já que existe relação de interdependência nas áreas ${ }^{6}$. A psicomotricidade critica a forma mecanicista de trabalho da Fisioterapia, da Educação Física e da Fonoaudiologia, por privar o participante de interferir na proposta de trabalho, tirando a espontaneidade nas ações, fazendo com que se perca a motivação na tarefa, pois o profissional obriga o participante a entrar no seu esquema de trabalho. O objetivo é que se busque adequar as condutas às necessidades do indivíduo, tornando a tarefa mais eficaz e satisfatória tanto para o profissional como para o participante ${ }^{7}$.

A psicomotricidade tem como elementos básicos: esquema corporal, lateralidade, estruturação espacial e orientação temporal, ritmo e equilíbrio ${ }^{8}$. Cada um deles será apresentado a seguir.

\section{Esquema corporal}

O esquema corporal pode ser definido como "uma intuição de conjunto ou um conhecimento imediato que temos de nosso corpo estático ou em movimento, na relação de suas diferentes partes entre si e, sobretudo, nas relações com o espaço e com os objetos que o circundam". . Conhecer as partes do corpo, suas funções e interações com ele mesmo e com o meio que o cerca é de fundamental importância na construção do esquema corporal e no desenvolvimento normal no âmbito motor, social e afetivo ${ }^{10}$.

As fases da evolução do esquema corporal podem ser divididas como:

1) Etapa do corpo submisso (de 0 a 1 ano): os movimentos são automáticos e subordinados a características congênitas inerentes (reflexos e automatismo). Os aspectos emocionais são mal controlados e fortes.

${ }^{5}$ BOATO, 1996.

${ }^{6}$ AUCOUTURIER et al., 1986.

${ }^{7}$ SANTINI, 1987.

${ }^{8}$ DE MEUR \& STAES, 1991.

${ }^{9}$ LE BOULCH, 1983.

${ }^{10}$ ARAÚJO, 2000.

Univ. Ci. Saúde, Brasília, v. 3, n. 2, p. 287-296, jul./dez. 2005 
2) Etapa do corpo vivido (de 1 a 4 anos): os movimentos são amplos, e a criança atua pelo método de tentativa e erro. Nesta etapa, aprende por imitação aos adultos e por suas experiências motoras. Essa fase ajuda a criar um esboço do esquema corporal.

3) Etapa do corpo descoberto (de 4 a 5 anos): a criança é capaz de nomear as diferentes partes do corpo, reconhece os segmentos corporais em um espelho, num colega ou em uma figura. Deve-se incentivá-la a relacionar, em uma tarefa, o que se faz com as regiões do corpo.

4) Etapa do corpo representado (de 6 a 10 anos): a criança obtém o esquema postural, associa movimentos, como correr e saltear. Nesta fase, devem-se priorizar posturas (composição de vários movimentos) que aprimorem o sentido e não enfatizar o trabalho em movimentos isolados em determinados segmentos corporais.

5) Etapa do corpo operatório (de 10 a 12 anos): a criança já conhece os segmentos do corpo, a disposição, as posições. Movimenta-se de forma a adquirir o domínio corporal por meio de exercícios de equilíbrio, coordenação, inibição e destreza que expressem, por intermédio de seu corpo, uma ação, um sentimento, uma emoção ${ }^{11}$.

\section{Lateralidade}

Durante a infância, define-se a dominância lateral na criança: terá mais força, agilidade, precisão, percepção tátil do lado direito ou esquerdo. A lateralidade dependerá das informações neurológicas, mas também é influenciada por vivências sociais $^{12}$.

Existem técnicas para descobrir a dominância lateral nos membros inferiores e superiores e nos olhos. Para determinar a lateralidade nos membros, elaboramse dinâmicas que evidenciem a força (pede-se para o indivíduo lançar uma bola em determinado alvo à sua frente com um braço e, depois, com o outro, o braço que usar primeiro, provavelmente, será o dominante) e a precisão (pede-se para o indivíduo desenhar um quadrado no papel com uma das mãos e, depois, com a outra, a primeira, provavelmente, será a dominante). Já para determinar a lateralidade dos olhos, pede-se que o indivíduo olhe pelo orifício de um caleidoscópio, por exemplo, com um olho, depois com o outro, o primeiro, provavelmente, será o dominante ${ }^{13}$.

A lateralidade contribui na formação da auto-imagem e da autocognição, no

${ }^{11}$ DE MEUR \& STAES, 1991; BOATO, 1996; DUARTE, 1992.

${ }^{12}$ DE MEUR \& STAES, 1991

${ }^{13}$ DE MEUR \& STAES, 1991; BOATO, 1996. 
esquema corporal, na percepção da simetria do corpo, na estrutura espacial. Existe diferença entre a lateralidade e o conhecimento de "esquerda-direita". O primeiro refere-se à dominância de um lado em relação ao outro, em nível de força e precisão, enquanto o segundo se refere ao domínio dos termos esquerda e direita ${ }^{14}$.

O conhecimento de esquerda e direita é imprescindível à estruturação espacial, pois serve para situar os seres e os objetos em determinado lugar. Essa compreensão dos dois lados acontece entre 5 ou 6 anos, e a reversibilidade (possibilidade de identificar a mão direita ou esquerda de um indivíduo à sua frente), entre os seis anos e meio ${ }^{15}$.

\section{Estruturação espacial e orientação corporal}

A estruturação espacial é a conquista de consciência da posição do próprio corpo em um lugar e da orientação que pode ter em relação às pessoas e às coisas ${ }^{16}$. Por isso, tem grande importância na vida da criança e do adulto, pois, a todo o momento, é-nos exigido situar nosso corpo em relação a outro indivíduo ou a algum objeto em determinado espaço ${ }^{17}$. A orientação temporal é a capacidade de situar-se em função da seqüência dos acontecimentos (antes/durante/depois), da duração dos intervalos (idéia de tempo longo e tempo curto; ritmo regular e irregular; cadência rápida e lenta), da renovação de certos períodos (dias, semanas, estações) ${ }^{18}$.

\section{Ritmo}

O ritmo é um fenômeno espontâneo e individual, cada pessoa possui o próprio, que começa pelos ritmos naturais internos (respiração, batimentos cardíacos). Ainda que careçam de ordenação, por tratar-se de parte efetiva do desenvolvimento psicomotor, o indivíduo organiza-os lentamente por meio de vivências sucessivas, na exploração de suas possibilidades ${ }^{19}$. Para o desenvolvimento do ritmo, podese eleger uma das técnicas, como dançar, bater palmas, bater os pés no chão, criar sons no próprio corpo. O que deve ser almejado é a livre expressão corporal, já que isso faz parte da personalidade ${ }^{20}$.

\footnotetext{
${ }^{14}$ LE BOULCH, 1992.

${ }^{15}$ COSTE, 1992.

${ }^{16}$ LE BOULCH, 1983.

${ }^{17}$ DE MEUR \& STAES, 1991.

${ }^{18}$ BOATO, 1996.

${ }^{19}$ LAPIERRE et al., 1985.

${ }^{20}$ DE MEUR \& STAES, 1991.
}

Univ. Ci. Saúde, Brasília, v. 3, n. 2, p. 287-296, jul./dez. 2005 
Souza \& Godoy

\section{Equilíbrio}

O dicionário de psicomotricidade define equilíbrio como:

"a habilidade de uma pessoa manter o controle do corpo, utilizando ambos os lados simultaneamente, um lado só, ou ambos, alternadamente. O equilíbrio se sustém pela interação de certo número de estruturas neuro-fisiológicas, sentidos e vias, como a visão, a excitação labiríntica e vestibular do reflexor do pescoço, as sensações táteis e proprioceptivas" ${ }^{\prime 2}$.

A psicomotricidade não se limita a considerar o equilíbrio como uma função motora influenciada apenas por estímulos táteis e proprioceptivos mas também inclui o aspecto psicológico, por influenciar a execução de determinados exercícios. Reações de medo e insegurança são manifestadas durante atividades que envolvem vivências de equilíbrio, portanto deve-se estar atento com respeito às variantes que interferem na execução do movimento corporal humano ${ }^{22}$.

\section{Interação de técnicas fisioterápicas aliadas a conceitos psicomotores}

Magalhães et al. (2003) realizaram estudo cujo objetivo foi comparar o desempenho perceptual-motor na idade escolar de crianças nascidas pré-termo e a termo. Participaram do estudo 2 grupos de crianças, com idades entre 5 e 7 anos. O grupo I foi constituído por 35 crianças, de famílias de baixa renda, nascidas até a $34^{\mathrm{a}}$ semana de gestação e/ou peso abaixo de $1500 \mathrm{~g}$, sem sinais de seqüela neuromotora. O grupo II foi constituído por 35 crianças nascidas a termo, com idade, sexo e nível socio-econômico equivalentes às crianças do grupo I. Foram aplicados os testes de Bender, acuidade motora e as provas de equilíbrio e tônus postural. As crianças pré-termo obtiveram escores significativamente inferiores na maioria dos testes. Tais resultados reafirmam a importância do acompanhamento da criança pré-termo até a idade escolar e indicam a necessidade de estimular o controle postural e a coordenação motora fina, mesmo nas crianças que não apresentam seqüelas neurológicas evidentes.

Corrêa et al. (1994) fizeram um trabalho que teve como objetivo avaliar a imagem e o esquema corporais das crianças portadoras de paralisia cerebral do tipo tetraparética espástica pela análise do desenho de si mesmas. Conseguiram

${ }^{21}$ HURTADO, 1991.

22 DE MEUR \& STAES, 1991; NEGRINE, 1987. 
detectar prováveis distúrbios de esquema corporal, tendo em vista que todas as crianças testadas não apresentaram imagem corporal correspondente à idade cronológica.

Abelheira \& Beresford, (2004) chamam a atenção dos profissionais da saúde sobre a importância da estimulação psicomotora precoce em pacientes com encefalopatia crônica infantil, pois são negligenciados pelos profissionais da saúde no que tange à humanização ao atendimento. Na visão dos autores, não há preocupação em criar alternativas para estimulação desses pacientes; assim, propõem as técnicas psicomotoras como auxiliar nos atendimentos fisioterapêuticos.

Valeski et al (2004) realizaram estudo de caso com um paciente com transtorno de déficit de atenção/ hiperatividade (TDAH), utilizando recursos lúdicoterapêuticos durante $\mathrm{o}$ atendimento fisioterapêutico. Observou-se, após o tratamento, sensível melhora da concentração e da coordenação motora do paciente, colaborando para sua independência funcional e as atividades pedagógicoeducacionais.

Pracidelli et al (2001) realizaram estudo com o objetivo de avaliar a percepção da imagem corporal pelos idosos internados no Serviço de Geriatria do Instituto Central do Hospital das Clínicas da Faculdade de Medicina da USP, com o intuito de observar discrepâncias e de verificar como a atuação conjunta da fisioterapia com a psicologia pode favorecer a recuperação dos indivíduos dessa faixa etária. As autoras encontraram alterações da imagem corporal em oitenta por cento dos idosos estudados, revelando a necessidade de um trabalho de esquema corporal em conjunto com técnicas fisioterápicas para a capacitação global desses indivíduos.

Wakahara \& Marques (1999) avaliaram a representação da imagem corporal de gestantes adolescentes e adolescentes não-grávidas e observaram que havia distorções quanto à imagem corporal e às dimensões do corpo nos dois grupos. Com isso, os resultados apresentados mostram a necessidade de trabalho de propriocepção corporal tanto para as não-grávidas como para as grávidas, possibilitando melhor desenvolvimento psicomotor.

Sá (1999) investigou mudanças motoras, sensórias e cognitivas em pacientes com paralisia cerebral (PC) submetidas à intervenção fisioterápica distintas pelas abordagens do método Kabat e Bobath. Verificou, ao final do estudo, que o método Kabat gerou mudanças motoras e sensoriais, enquanto o método Bobath gerou evolução nos padrões cognitivos. Ambos os métodos ajudaram o desenvolvimento neurocomportamental e no desempenho psicomotor dos pacientes com PC.

Mello \& Marques (1995) apresentaram um trabalho cujo objetivo era verificar como os fibromiálgicos representavam a imagem corporal por pontos anatômicos tocados pelo fisioterapeuta. Observaram que os pacientes apresentavam dificul- 
dades em projetar a imagem corporal correta. As autoras salientam a importância em associar as técnicas fisioterápicas com as psicomotoras para um tratamento que vise à globalidade dos pacientes e não apenas ao funcionamento músculoesquelético.

Gandolfi \& Skora (2001) realizaram um estudo sobre a fisioterapia preventiva em grupos de terceira idade e verificaram o aumento da qualidade de vida, a melhora na sociabilização, a diminuição de ingestão de medicamentos, o aumento da auto-estima. As pesquisadoras realizaram atividades em grupo, recursos lúdicoterápicos, como bolas suíças, dinâmicas de grupo, cantigas populares para alcançar os benefícios.

\section{Considerações finais}

A fisioterapia objetiva restabelecer a funcionalidade motora, minimizando seqüelas instaladas. O paciente e o fisioterapeuta devem aprender a lidar com novos desafios durante o processo reabilitacional pela condição limitante apresentada, portanto conceitos da psicomotricidade, como aprendizagem motora, esquema corporal, percepção sensório-motora, organização espacial, biorritmo, devem ser utilizados para traçar a conduta terapêutica.

A interação entre técnicas fisioterápicas e a psicomotricidade pode tornar o tratamento mais efetivo e significativo tanto para o paciente como para o fisioterapeuta, uma vez que apenas a utilização das técnicas fisioterápicas não permite ao profissional a observação de alguns pontos durante a avaliação e o tratamento, tais como, os aspectos afetivo e emocional, a avaliação da imagem corporal, a percepção espacial, a espontaneidade do indivíduo durante a terapia. A negligência a esses pontos pode tornar $\mathrm{o}$ atendimento algo desinteressante para o paciente, dificultando sua adesão ao tratamento. Assim, observa-se a necessidade de novos trabalhos associando técnicas fisioterápicas às psicomotoras no tratamento fisioterapêutico, já que, na literatura atual, existem poucos artigos que abordem a interação entre essas áreas do conhecimento.

\section{Referências}

ABELHEIRA, L. A.; BERESFORD H.. O valor moral de uma estimulação precoce humanizada na encefalopatia crônica infantil. In: Fisioterapia Brasil - vol 5 n 4 julho/ agosto de 2004.

ARAÚJO C. A. Desenvolvimento do esquema corporal. In: Temas sobre desenvolvimento. 2000, 9 (52): 56-58. 
AUCOUTURIER, B.; DARAULT, I. EMPINET, J.L.. A prática psicomotora: reeducação e terapia. Porto Alegre: Artes Médicas, 1986. p. 7-11.

BOATO, E. M. Introdução á educação psicomotora: a vez e a voz do corpo na escola. Brasília. ASSEFE - Associação de Assistência aos Servidores da FEDF, 1996.

BURNS, Y.R.; MACDONALD J. Fisioterapia e crescimento na infância. São Paulo: Santos Livraria e Editora, 1999. p.34-46.

CONSELHO FEDERAL DE FISIOTERAPIA E TERAPIA OCUPACIONAL.

Resolução COFFITO - 80 de 09 de maio de 1987, publicado no D.O.U. nº 093 - de 21/05/ 87 seção 1, p. 7609.

CORRÊA, F. I.; COSTA, T. T.; FERNANDES, M. V. Estudo da imagem e esquema corporal de crianças de paralisia cerebral tipo tetraparética espástica. In: Fisioterapia Brasil, 2004; S(2): 131-135.

COSTE, J.C. A psicomotricidade. 4. ed. Rio de Janeiro: Guanabara Koogan S.A., 1992. p. 52-60.

DE MEUR A.; STAES L. Psicomotricidade: educação e reeducação: níveis maternal e infantil. São Paulo: Manole, 1991. p. 9-18.

DUARTE, R.M.P. Superdotados e psicomotricidade: um resgate à unidade do ser. Petrópolis: Vozes, 1992. p. 79-81.

GANDOLFI, L. M.; SKORA, M. C. Fisioterapia preventiva em grupos na terceira idade. In: Fisioterapia em Movimento, v.13, n.2, p. 55-62, outubro/ 2000-março/ 2001.

HURTADO, J. G. G. M. Dicionário de psicomotricidade. Porto Alegre: PRODIL, 1991. p. 50.

LAPIERRE, A. \& AUCOUTURIER, B. Associação de contrastes: estruturas e ritmos. São Paulo: Manole, 1985. p. 180-206.

LE BOULCH, J. A educação pelo movimento: a psicocinética na idade escolar. Porto Alegre: Artes Médicas, 1983.p. 37.

- O desenvolvimento psicomotor: do nascimento até 6 anos. Porto Alegre: Artes Médicas, 1992. p. 30.

MAGALHÃES, L.C. et al. Estudo comparativo sobre o desempenho perceptual e motor na idade escolar em crianças nascidas pré-termo e a termo. In: Arq. NeuroPsiquiatr., São Paulo.2003 61 (2A).

MELLO, M.; MARQUES, A. P. A imagem corporal representada pelos fibromiálgicos: um estudo preliminar. In: Rev. Fisioter. Univ. São Paulo, v. 2, n.2, p. 87-93, ago./ dez., 1995.

NEGRINE, A. Coordenação psicomotora e suas implicações. Porto Alegre: Presença, 1987.p. 29.

NICIDA, D.P. Fisioterapia: uma ciência em construção. R. Fisioter. UniFMU. São Paulo. 2004. 2, (3). p. 7-11.

PRACIDELLI, F.; el al. A imagem corporal dos idosos internados na enfermaria do 
serviço de geriatria: uma visão fisioterápica e psicológica. Mundo saúde (1995); 25(4):404-410, out.-dez. 2001.

SÁ, C. S. C. Mudanças motoras, sensoriais e cognitivas em crianças com paralisia cerebral espástica diparética submetidas a intervenção fisioterápica pelas abordagens Kabat ou Bobath. Rev. Fisioter. Univ. São Paulo, v. 6, n.2, p.178, jul./dez., 1999.

SANTIN, S. Educação física: uma abordagem fisiológica da corporeidade. Ijuí: Unijuí, 1987. p. 25.

VALESKI, A.; COELHO, B. L. P.; RODRIGUES, M. C. Transtorno de déficit de atenção/ hiperatividade: tratamento fisioterapêutico com abordagem ludoterapêutica. In: Fisio Brasil, vol 5 nº 1 janeiro/fevereiro de 2004.

WAKAHARA, A. S.; MARQUES, A. P. Avaliação quantitativa da imagem corporal de gestantes adolescentes primigestas pobres da cidade de São Paulo. Rev. Fisioter. Univ. São Paulo, v.6, n.2, p.174, jul./dez., 1999. 